www.jmscr.igmpublication.org

Impact Factor (SJIF): 6.379

Index Copernicus Value: 71.58

ISSN (e)-2347-176x ISSN (p) 2455-0450

crossrefDOI: https://dx.doi.org/10.18535/jmscr/v6i6.82

Journal Of Medical Science And Clinical Research

\title{
Cerebral Venous Sinus Thrombosis-A Study of Clinicoaetiological Profile
}

\author{
Authors \\ Prof Manoranjan Acharya ${ }^{1}$, Prof Prativa Panda \\ Prof.\& HOD, Dept. of Neurology, VIMSAR, Burla. Odisha, India \\ ${ }^{2}$ Prof.\& HOD, Dept. of Anesthesiology, P R M Medical College, Baripada, Odisha, India \\ Corresponding Author \\ Prof Prativa Panda \\ Email: prativa.anaes@gmail.com, Mob no-9437080531
}

\begin{abstract}
Background \& Objective: Cerebral venous sinus thrombosis (CVST) remains a diagnostic \& therapeutic challenge for the clinician. This study analyses the epidemiological factor, clinical profile, predisposing factor \& radiological characteristics of 41 patients of radiological confirmed cases of CVST.

Method: This study comprises 41 consecutive patients with radiologically confirmed diagnosis of CVST who were admitted to a tertiary care hospital in western Odisha for the period from January 2014 to February 2017.The diagnosis was confirmed by MRI Brain \& MR Venography. The epidemiological, clinical \& radiological, laboratory evaluation done \& datas were recorded in a structured proforma.

Result: Total number of patients were 41.Female outnumbered males in the ratio of 29:12.The mean age of presentation was 32.1(age range 15-66 years).The most frequent predisposing factor was OCP use in females \& infection \& alcoholism in males. The mean duration of symptoms before presentation was $7(+/-$ 3.1) days. Most common presenting feature was headache. Transverse sinus sinus was most commonly involved followed by Superior sagital sinus.

Conclusion: CVST presents with varied symptom \& sign. Females were mostly affected. Headache was the most frequent symptom.OCP use in females \& infection in males were the most common presenting feature.
\end{abstract}

\section{Introduction}

Cerebral venous sinus thrombosis (CVST) is the thrombosis affecting cerebral veins \& sinuses. It can mimic many neurological conditions \& can present as headache, benign intra cranial hypertension $(\mathrm{BIH})$, encephalopathy or stroke ${ }^{[1]}$. Recent reports indicate that CVST incidence is more common than previously assumed due to greater awareness \& availability of newer imaging modalities $^{[2]}$. Previously most reported incidence were based on autopsy studies and range from 0.1 $\%$ of 12500 consecutive autopsies to $9 \%$ of all death resulting from cerebrovascular causes ${ }^{[3]}$. There is a greater prevalence of CVST in the puerperal period in south India ${ }^{[4]}$. The data from NIMHANS Bengaluru indicate that $90 \%$ of CVST were women \& majority were in puerperal period. We conducted this study to know the clinicoaetiological profile of CVST cases in this region.

\section{Methods}

This prospective study comprised of 41 cases with radiologically proven CVST. This study was conducted at a tertiary care hospital in western 
Odisha between the period from January 2014 to February 2017. The epidemiological, clinical \& radiological datas were recorded in a structured proforma. Detailed neurological evaluation were done. Laboratory evaluation included CBC, ESR, routine blood chemistry along with prothrombin time, APTT, INR, CRP, ANA \& d-Dimer assay. The aetiological work up for thrombophillia screening like protein $\mathrm{C} \& \mathrm{~S}$, antithrombin III, lupus anticoagulant, anti cardiolipin antibody (ACLA), serum homocystiene \& factor V leiden mutation were done.

\section{Results}

Total 41 numbers of radiologically confirmed CVST cases were included in this study. Female outnumbered males in the ratio of 29:12.The mean age of presentation was 32.1 (age 15-66 years). Most of the cases were in the age group of second to fourth decade. (Table-1)

Table-1 Distribution of patients according to sex $\&$ age

\begin{tabular}{|l|c|c|}
\hline \multicolumn{1}{|c|}{ SEX } & Number & Percentage \\
\hline Male & 12 & 29.3 \\
\hline Female & 29 & 70.7 \\
\hline AGE IN YEARS & & \\
\hline$<20$ & 7 & 17.0 \\
\hline $21-40$ & 27 & 65.8 \\
\hline $41-60$ & 5 & 12.1 \\
\hline$>60$ & 2 & 4.8 \\
\hline
\end{tabular}

Most common presenting feature was headache. Other presenting features were vomiting, seizure, altered sensorium, motor sensory deficit \& papilloedema. The details of clinical presenting feature is recorded in table-2.

Table-2-Initial clinical presentation of patients

\begin{tabular}{|l|c|c|}
\hline Syptom/sign & Number of patients & Percentage \\
\hline Headache & 38 & 92.6 \\
\hline Vomiting & 30 & 73.1 \\
\hline Focal seizure & 9 & 21.9 \\
\hline Generalised seizure & 7 & 17.0 \\
\hline Altered sensorium & 9 & 21.9 \\
\hline Aphasia & 4 & 9.7 \\
\hline Motor deficit & 12 & 29.2 \\
\hline Sensory deficit & 7 & 17.0 \\
\hline $\begin{array}{l}\text { Cranial nerve } \\
\text { involvement }\end{array}$ & 8 & 19.5 \\
\hline Papilloedema & 20 & 48.7 \\
\hline
\end{tabular}

Presentation was acute in $6(14.6 \%)$, subacute in $30(73.2 \%) \&$ chronic in $5(12.2 \%)$ cases. (Table3)

Table-3 Distribution of patients according to onset of symptoms

\begin{tabular}{|l|c|c|}
\hline Presantation & Number & Percentage \\
\hline Acute & 6 & 14.6 \\
\hline Subacute & 30 & 73.2 \\
\hline Chronic & 5 & 12.2 \\
\hline
\end{tabular}

Four common type of syndromic presentation were found. These are Stroke like presentation 24 case $(58.5 \%)$, isolated seizure 3 cases $(7.3 \%)$, encephalopathy 2 cases $(4.9 \%) \& \mathrm{BIH}$ like presentation 12 cases. (Table-4)

Table-4 Syndromic presentation types

\begin{tabular}{|l|c|c|}
\hline Types & Number & Percantage \\
\hline Stroke like & 24 & 58.5 \\
\hline Isolated seizure & 3 & 7.3 \\
\hline Encephalopathy & 2 & 4.9 \\
\hline $\begin{array}{l}\text { Benign intracranial } \\
\text { hypertension }\end{array}$ & 12 & 29.2 \\
\hline
\end{tabular}

Known risk factor were present in 19 (46.4\%) cases. Among the risk factors OCP use was the most common risk factor amongst females followed by peripartum state.OCP was used in most of the cases for menstrual regularisation. Local infection (mastoiditis, CSOM, sinusitis \& meningitis) were found as a risk factor in $2(4.8 \%)$ cases. Diabetes mellitus was found to be associated with $1(2.4 \%)$ case. In 10 cases thrombophillia factor assay was done. 3(30\%) cases had one or more coagulation factor abnormalities. Alcoholism, anaemia \& dehydration were among the other risk factors. Multiple risk factor were present in $3(7.3 \%)$ of cases. Infection \& alcoholism were the most common aetiological factor in male patients. No risk factor were detected in $22(53.6 \%)$ cases. (Table-5) 
Table-5 Predisposing factor (Number \& percentage more than 100 is due to presence of multiple risk factors)

\begin{tabular}{|l|c|c|}
\hline Factor & Number & Percentage \\
\hline Oral contraceptive & 5 & 12.2 \\
\hline Pregnancy/puerperium & 2 & 4.8 \\
\hline Head trauma & 1 & 2.4 \\
\hline Local infection & 2 & 4.8 \\
\hline H/O of DVT/CVT & 1 & 2.4 \\
\hline Diabetes mellitus & 1 & 2.4 \\
\hline Anaemia & 1 & 2.4 \\
\hline Alcoholism & 2 & 4.8 \\
\hline Prothrombotic factor & 3 & 7.3 \\
\hline Dehydration & 1 & 2.4 \\
\hline Multiple risk factor & 3 & 7.3 \\
\hline $\begin{array}{l}\text { No detectable risk } \\
\text { factor }\end{array}$ & 22 & 53.6 \\
\hline
\end{tabular}

Transverse sinus involvement followed by superior sagital sinus involvement were the most common findings. Multiple sinus involvement were more common than single sinus involvement.

Table-6 Venous sinus involvement (Number \& percentage more than 100 is due to multiple sinus involvement)

\begin{tabular}{|l|c|c|}
\hline Sinus & Number & Percentage \\
\hline Superior sagital & 18 & 43.9 \\
\hline Transverse & 21 & 51.2 \\
\hline Straight & 5 & 12.1 \\
\hline Sigmoid & 16 & 39.0 \\
\hline Cavernous & 1 & 2.4 \\
\hline Jugular vein & 1 & 2.4 \\
\hline Cortical vein & 2 & 4.8 \\
\hline Multiple sinus & 23 & 56.0 \\
\hline
\end{tabular}

\section{Discussion}

In this series of 41 cases of CVST there is a female preponderance. It correlates with other studies $^{[5,6,7,8]}$. Recent studies done in India \& abroad show a male dominance. The increased incidence of female cases in our series relates to OCP use \& puerperal hypercoagulable state. The mean age in the present study was 32.1 year. Larger study series from India show mean age varying from 31.3 to 48.7 years ${ }^{[9]}$.

Headache, vomiting, papilloedema \& seizure were the most common presenting feature in this study. In the NIVSAR cohort $88.3 \%$ patients had headache ${ }^{[10]}$. In most of the cases headache precedes the development of all other features. Seizure was seen in 35\%-55\% of all patients with CVST even with a higher frequency $(76 \%)$ in peripartum $\mathrm{CVST}^{[11]}$. In a retrospective study Kalita et al found a predominance of seizure in CVST cases ${ }^{[12]}$.

Paplloedema was found very commonly in chronic cases. Sixth cranial nerve involvement was present next to papilloedema.

Four common type of syndromic presentation were found. These are Stroke like presentation $(58.5 \%)$, isolated seizure (7.3\%), encephalopathy $(4.9 \%) \&$ BIH like presentation (29.2\%). In NIVSAR cohort syndrome of raised intracranial pressure was found in $18.2 \%$ of patients. In other studies it was found in 10- 29\% of cases. Patients presenting as encephalopathy is described in literature in varying proportion from 6-29\% of cases ${ }^{[13,14]}$.

Among the risk factors OCP use was the most common risk factor amongst females followed by peripartum state.OCP was used in most of the cases for menstrual regularisation. Our study correlates with previous studies done in India. The recent NIVSAR cohort study reported a low incidence of CVST in postpartum or pregnant state. Better obstetric care could be the possible cause for this change.

There is sufficient evidence that OCP use \& CVST has a causal relationship \& the great majority of young non pregnant women with CVST are OC user and the risk increases with the presence of hereditary prothrombotic state. In the international study on cerebral vein \& dural sinus thrombosis (ISCVT) cohort of 624 adults with CVST $46 \%$ were on OC pill ${ }^{[10]}$. In a study by Khelani et al show an incidence of $14 \%^{[15]}$. In the NIVSAR study $11.4 \%$ had usage of OCP.

Local infection (mastoiditis, CSOM \& sinusitis) \& meningitis were found as a risk factor in $4.8 \%$ cases .Infection as a predisposing factor has been reported by various authors ${ }^{[16,17,18]}$. Improved health awareness, hygiene \& availability of antibiotic \& chemotherapeutic agents has reduced the incidence of CVT in these cases. 
Diabetes mellitus was found to be associated with $2.4 \%$ of cases. In the literature few case reports are available which reveals association of diabetes $\&$ its complications associated with CVST. In our series none of our diabetes patients presented with complications.

In 10 cases thrombophillia factor assay was done. $30 \%$ cases had one or more coagulation factor abnormalities. Prothrombotic condition as a risk factor has been described in literature from the western countries. From India Pai et al found 18\% cases to be positive for thrombophilia marker ${ }^{[16]}$.

Transverse sinus involvement followed by superior sagital sinus involvement were the most common findings. Multiple sinus involvement were more common than single sinus involvement. Study from India \& middle east show more common involvement of superior sagital sinus $^{[9,19,20]}$.

\section{Conclusion}

Cortical venous sinus thrombosis is an important $\&$ treatable cause of Stroke. Female cases outnumbered males in our series. Majority of the patients were in the age group of third to fourth decade. Headache associated with raised ICP was the most common clinical presentation. Among the risk factors OCP use in females \& ENT infection and alcoholism in males were common. MRV study showed incidence of transverse sinus involvement more common than others. Further studies with inclusion of more number of patients are necessary. .

\section{References}

1. Ehtisam A, Stern BJ. Cerebral venous thrombosis: A review Neurologist 2006;12:32-8

2. Yadollahikhales G, Borhani-Haghighi A, Safari A, Wasay M, Edgell R Cerebral venous sinus thrombosis. GMJ 2016;5 Suppl 1;48-61.

3. Dash D, Prasad K, Joseph L. Cerebral venous thrombosis; An Indian perspective. Neurology India 2015;63:318-28
4. Padmavati S,Gupta S,Singh B. A clinical study of 44 cases of hemiplegia of adult women. Neurology India 1957;5:59-65.

5. Nagpal RD. Dural sinus and cerebral venous thrombosis. Neurosurgery Rev 1983;6:155-60

6. Srinivasan K, Natarajan M. Cerebral venous and arterial thrombosis in pregnancy and puerperium.Neurol India 1974;22:131-40

7. Srinivasan K, Natarajan M. Crebral venous and sinus thrombosis in pregnancy and ppuerperium. A study of 135 patients. Angiology 1983;34:731-46.

8. Nagaraja D, Taly AB. Cerebral venous thrombosis. J Assoc Physicians India 1987;35:876.

9. Narayan D,Kaul S,Ravishankar K, Suryaprabha T, et al. Risk factors, clinical profile, and long term outcome of 428 patients of cerebral sinus venous thrombosis: Insights from Nizams Institute Venous stroke Registry, Hyderabad (India). Neurol India 2012;60:154-9.

10. Ferro JM,Canhao P,Stam J, Bousser MG, Barinagarrementeria F, ISCVT Investigators. Prognosis of cerebral vein and Dural Sinus Thrombosis: Result of the International study on Cerebral vein and Dural Sinus Thrombosis (ISCVT). 2004;35:664-70

11. Ferro JM,Correia M, Pontes C, Baptista MV,Pita F, Cerebral venous thrombosis Potuguese collaborative study group (venoport). Cerebral vein and dural sinus thrombosis in Portugal:1980-88. Cerebrovasc Dis 2001;11:177-82.

12. Kalita J, Chandra S, Mishra UK. Significance of seizure in cerebral venous sinus thrombosis. Seizure 2012;21:639-42.

13. Nagaraja D, Wassy M, Christophor M, Santosh V. Cerebral venous sinus Thrombosis. In Chopra JS, Sawhney IMS editor. Neurology in Tropics, $2^{\text {nd }}$ ed. Elsevier, 2016;669-679. 
14. Caso V, Agnelli G, Paciaroni M, editors. Hand book on cerebral venous thrombosis. Karger Medical and Scientific Publishers; 2008,23-54.

15. Khealani BA, Wasay M, Saadah M, Sutana E, Mustafa S, Khan FS, et al Cerebral venous thrombosis; A descriptive multicenter study of patients in Pakistan and Middle East. Stroke 2008;39:2707-11.

16. Pai N, Ghosh K, Shetty S. Hereditary thrombophillia in cerebral venous thrombosis; A study from India. Blood Coagul Fibrinolysis 2013;24: 540-3.

17. Felicio AC, Fukujima AM, Fiorot JA jr, do Prado GF, et al. Cerebral venous thrombosis and Hepatitis: case report. Arq Neuropsiquiatr 2006;64:1041-42.

18. Kesler A, Pomeranz IS, Huberman M, etal. Cerebral venous thrombosis and chronic active hepatitis as part of the antiphospholipid syndrome. Postgrad Med J 1996;72:690-92.

19. Algherbawe MT, Khan FY, Abonoff SS, et al. Clinical charecteristics and outcome of cerebral venous thrombosis: A 4- year Hospital based study from 2008 to 2011. Libyan J Med Sci 2017;1:36-9.

20. Wasay M, Azeemuddin M. Neuroimaging of cerebral venous Thrombosis. J Neuroimaging.2005;15:118-128. 